\title{
Avaliação de pontas de pulverização hidráulicas na aplicação de fungicida em feijoeiro
}

\author{
Evaluation of hydraulic spray nozzles for fungicide application on common beans
}

\author{
João Paulo Arantes Rodrigues da Cunha ${ }^{1}$ Mauri Martins Teixeira ${ }^{2}$ \\ Rogério Faria Vieira ${ }^{3}$
}

\section{RESUMO}

As pontas de pulverização são um dos componentes mais importantes dos pulverizadores hidráulicos para aplicação de agrotóxicos por afetarem as características do jato emitido. Este estudo teve como objetivo avaliar três pontas de pulverização hidráulicas (jato plano padrão, jato plano antideriva e jato cônico vazio) no controle de doenças do feijoeiro. O fungicida clorotalonil foi aplicado aos 20,30, 40 e 50 dias após a emergência (DAE), num volume de água de $125 \mathrm{~L} \mathrm{ha}^{-1}$. Para comparação, foi utilizada uma testemunha que não recebeu o defensivo. Empregou-se o delineamento em blocos ao acaso, com quatro repetições. Os primeiros sintomas da antracnose, da mancha-angular e da ferrugem foram observados já aos 20 DAE. A densidade de gotas obtida com as três pontas de pulverização foi superior a 60 gotas $\mathrm{cm}^{-2}$. As três pontas proporcionaram controle satisfatório das doenças e não houve diferença entre pontas. Em média, o aumento da produtividade devido ao fungicida foi de $76 \%$, em relação à testemunha.

Palavras-chave: tecnologia de aplicação, agrotóxico, Phaseolus vulgaris L., ferrugem, antracnose, manchaangular.

\section{ABSTRACT}

The spray nozzles are one of the most important components of pesticide hydraulic sprayer because they affect the characteristics of the emitted spray. The objective of this study was to evaluate three hydraulic spray nozzles (standard flat fan, low drift flat fan and hollow cone) for bean diseases control upon application of the fungicide chlorothalonil applied at 20, 30, 40 and 50 days after emergency (DAE) in a water volume of $125 \mathrm{~L}$ $h a^{-1}$. For comparison, a non-treated plot was used. A randomized complete-block design with four replications was used. The first symptoms of anthracnose, angular leaf spot and rust were observed at $20 \mathrm{DAE}$. The droplet density obtained with the three spray nozzles was above 60 droplets $\mathrm{cm}^{-2}$. The fungicide applied with the three nozzles provided satisfactory control of the diseases and there were no differences among nozzles. On average, bean yield increased $76 \%$ due to the fungicide applications.

Key words: application technology, pesticide, Phaseolus vulgaris L., rust, anthracnose, angular leaf spot.

\section{INTRODUÇÃO}

A cultura do feijão tem sido, tradicionalmente, caracterizada como segmento atrasado do setor agrícola brasileiro. A atividade está comumente associada ao pequeno produtor, ao emprego de pouca tecnologia e a grandes oscilações na produção e na produtividade. No entanto, essa situação vem-se alterando nos últimos anos, já se percebendo nova dinâmica na produção, que vem influenciando a rentabilidade da atividade. Conseqüentemente, o feijão está deixando de ser lavoura de subsistência para se transformar em cultura tecnificada.

O risco parece ser um dos principais fatores desestimuladores da exploração do feijão por grandes produtores. A cultura é suscetível a numerosas doenças. Mais de 45 delas podem ocorrer durante o desenvolvimento da cultura, embora aproximadamente dez sejam realmente importantes (BORÉM \& CARNEIRO, 1998). Essas doenças contribuem para a baixa produtividade do feijoeiro no Brasil. Uma

\footnotetext{
${ }^{1}$ Instituto de Ciências Agrárias, Universidade Federal de Uberlândia. Campus Umuarama, 38400-902, Uberlândia, MG, Brasil. mail: jparc@bol.com.br. Brasil. Autor para correspondência.

${ }^{2}$ Universidade Federal de Viçosa, Viçosa, MG, Brasil. E-mail: mauri@ufv.br

${ }^{3}$ Embrapa/Epamig. Brasil. E-mail: rfvieira@epamig.br
} 
alternativa para contornar o problema é a aplicação de fungicidas, que evitam ou diminuem a severidade das doenças e, conseqüentemente, podem aumentar a produtividade da cultura (DUDIENAS et al., 1990).

$\mathrm{Na}$ maioria das vezes, dá-se muita importância ao produto fitossanitário a ser aplicado e pouca atenção à tecnologia de aplicação. No entanto, além de conhecer o produto a ser aplicado, também é necessário dominar a forma adequada de aplicação, de modo a garantir que o produto alcance o alvo de forma eficiente, minimizando-se as perdas.

No caso do feijoeiro, é comum a aplicação de fungicida utilizando altos volumes de calda com gotas de pequeno tamanho, o que pode causar muita deriva. Segundo MURPHY et al. (2000), o desvio da trajetória das partículas liberadas pelo processo de aplicação é influenciado pela velocidade dos ventos, pela altura da barra, pela velocidade de deslocamento do equipamento aplicador e pelo tamanho de gotas. Estudos têm mostrado que, durante a pulverização, à medida que aumenta a proporção de gotas com diâmetro inferior a $100 \mu \mathrm{m}$ também aumenta a deriva (SDTF, 1997). Biologicamente, no entanto, altos volumes de calda aplicados com gotas de pequeno diâmetro são bastante eficazes no controle de doenças (WALKLATE, 1992 e CROSS et al., 2001). Portanto, alternativas a essa forma de aplicação devem ser estudadas, visando tornar a aplicação mais segura ambientalmente.

A escolha e o uso adequado de pontas de pulverização são essenciais para a melhoria das condições de precisão e segurança na aplicação de defensivos (WOMAC et al., 1997). O conhecimento das condições de trabalho e, principalmente, do desempenho operacional das pontas é básico para uma aplicação eficiente (CHRISTOFOLETTI, 1999). Segundo JOHNSON \& SWETNAM (1996), a seleção apropriada das pontas é o principal fator determinante da quantidade aplicada por área, da uniformidade de aplicação, da cobertura obtida e do risco potencial de deriva.

Existem no mercado vários tipos de pontas hidráulicas, com usos definidos para diferentes condições. Entre as mais usadas, destacam-se as de jato cônico vazio e as de jato plano, as quais, dependendo da pressão e do ângulo de abertura, podem causar muita deriva. Para contornar esse problema, os fabricantes lançaram no mercado pontas com potencial antideriva. Um dos modelos, de pontas de jato plano antideriva, é dotado de um pré-orifício, localizado antes da abertura para a formação do jato, que produz gotas de maior diâmetro.

Para a aplicação de fungicida nos feijoeiros, as pontas mais utilizadas são as de jato cônico vazio.
Entretanto, em virtude do seu espectro de gotas ser muito susceptível à deriva, tem-se tentado utilizar também as de jato plano. Estas, entretanto, podem comprometer a cobertura das plantas, em virtude de as gotas serem de maior tamanho, principalmente no caso das pontas de jato plano antideriva. Conseqüentemente, pode haver menor controle de doenças. De forma geral, gotas pequenas são facilmente transportadas pelo vento, porém propiciam cobertura maior do alvo, condição desejada, principalmente, quando se utilizam fungicidas de contato.

Este trabalho teve como objetivo testar diferentes pontas de pulverização hidráulicas na aplicação de fungicida no feijoeiro.

\section{MATERIAL E MÉTODOS}

A primeira parte deste estudo foi conduzida em campo, durante a estação de inverno do ano de 2002, em área experimental do Departamento de Fitotecnia da Universidade Federal de Viçosa, município de Coimbra, MG, à altitude de $716 \mathrm{~m}$, longitude de $42^{\circ} 48^{\prime} \mathrm{S}$ e latitude de $20^{\circ} 51^{\prime} \mathrm{W}$. Utilizouse a cultivar de feijão do tipo carioca Pérola, semeada no espaçamento entre fileiras de $0,50 \mathrm{~m}$, com cerca de 15 sementes $\mathrm{m}^{-1}$. Essa cultivar foi lançada em 1996 e é uma das mais plantadas no País. Apesar do porte semiprostrado (tipo III), produz ramas na parte superior da planta, que se entrelaçam, não a deixando tombar muito.

O preparo do solo foi feito com uma aração e duas gradagens. A adubação foi realizada utilizandose $700 \mathrm{~kg} \mathrm{ha}^{-1}$ do formulado 4-14-8, no plantio, e $50 \mathrm{~kg}$ $\mathrm{ha}^{-1}$ de nitrogênio em cobertura, na forma de sulfato de amônio, aos 18 dias após a emergência (DAE). Aplicaram-se, também, em pulverização, $80 \mathrm{~g} \mathrm{ha}^{-1} \mathrm{de}$ molibdênio aos 19 DAE.

Realizou-se o controle de plantas daninhas e de insetos usando-se agrotóxicos, aplicados nas seguintes doses do ingrediente ativo: herbicida fomesafen, na dose de $100 \mathrm{~g} \mathrm{ha}^{-1}$, herbicida fluazifopp-butil, na dose $125 \mathrm{~g} \mathrm{ha}^{-1}$, inseticida deltametrina, na dose de $5 \mathrm{~g} \mathrm{ha}^{-1}$, e inseticida monocrotofós, na dose de $300 \mathrm{~g} \mathrm{ha}^{-1}$. A área experimental foi irrigada via aspersão convencional.

O ensaio foi conduzido no delineamento em blocos ao acaso, com quatro repetições. Foram avaliados três tipos de pontas de pulverização (jato cônico vazio, jato plano padrão e jato plano antideriva) no controle de doenças da parte aérea do feijoeiro. Além disso, foi avaliado um tratamento adicional sem o recebimento de fungicida. 
Foi utilizado o fungicida clorotalonil, na dose recomendada pelo fabricante $\left(1,5 \mathrm{~kg} \mathrm{ha}^{-1}\right.$ do ingrediente ativo). Trata-se de um fungicida protetor, formulação pó-molhável, na concentração $750 \mathrm{~g} \mathrm{~kg}^{-1}$.

$\mathrm{O}$ produto foi aplicado quatro vezes, em intervalos de dez dias, a partir de 20 DAE. Para a aplicação, utilizou-se um pulverizador costal de pressão constante $\left(\mathrm{CO}_{2}\right)$, dotado de uma barra portabicos de dois metros. A altura da barra em relação à cultura e o espaçamento entre bicos foram de $0,5 \mathrm{~m}$. Durante as aplicações, monitoraram-se temperatura, umidade relativa e velocidade do vento.

Utilizaram-se pontas de pulverização hidráulicas fabricadas em alumina revestida por poliacetal: ATR Brown, API 110-02 e ADI 110-02 (todas fabricadas pela Albuz, Ceramiques Techniques Desmarquest, Evreux, France). As pontas de jato cônico vazio ATR (alumina turbulência), de acordo com o fabricante, são indicadas para aplicações de fungicidas e inseticidas com pressão superior a 300 $\mathrm{kPa}$ em barras de pulverização, apresentando ângulo de abertura do jato de $80^{\circ}$ e vazão nominal de $0,48 \mathrm{~L}$ $\min ^{-1}$, a pressão de $500 \mathrm{kPa}$. As pontas de jato plano padrão API (alumina plástico ISO) e de jato plano antideriva ADI (alumina drift ISO) ensaiadas são de uso geral e apresentam ângulo de abertura do jato de $110^{\circ}$ e vazão nominal de $0,80 \mathrm{~L} \mathrm{~min}^{-1}$, a pressão de $300 \mathrm{kPa}$. Estas proporcionam aplicações uniformes quando os jatos de pulverização se sobrepõem. São recomendadas para trabalhar a pressões entre $200 \mathrm{e}$ $400 \mathrm{kPa}$, com altura mínima da barra de $40 \mathrm{~cm}$ em relação ao alvo. As pontas ADI apresentam um préorifício que permite a formação de gotas de maior diâmetro.

A velocidade de deslocamento do aplicador foi de $4 \mathrm{~km} \mathrm{~h}^{-1}$, quando se utilizou a ponta ATR Brown, e de $6 \mathrm{~km} \mathrm{~h}^{-1}$ para as restantes. A pressão de operação foi de $200 \mathrm{kPa}$ para as pontas de jato plano e de 400 $\mathrm{kPa}$ para a ponta de jato cônico, para atingir o volume de pulverização selecionado: $125 \mathrm{~L} \mathrm{ha}^{-1}$.

A avaliação da eficácia do fungicida no controle das doenças foi feita mediante a comparação da severidade de doenças e dos componentes da produção entre parcelas tratadas com fungicida e parcelas não-tratadas (testemunha).

A avaliação da severidade foi realizada a partir do aparecimento dos primeiros sintomas e, depois, a intervalos de aproximadamente dez dias, totalizando seis avaliações. A primeira avaliação de severidade foi feita aos 30 DAE. Para tal, utilizaramse as escalas diagramáticas propostas por GODOY et al. (1997). Estas escalas, específicas para as doenças do feijoeiro (antracnose, mancha-angular e ferrugem), levam em conta o mínimo e o máximo de sintomas encontrados no campo, representando os sintomas da forma o mais próxima possível do observado nas plantas e com níveis intermediários que consideram as limitações da acuidade visual humana. Ressalta-se que, na avaliação, marcaram-se 10 plantas, escolhidas ao acaso em cada parcela e, em cada planta, três folhas: uma na parte inferior, outra na parte intermediária e a terceira na parte superior da planta. As médias dessas avaliações constituíram a severidade média da doença.

Com os dados da severidade de doenças, procedeu-se a construção da curva de progresso da doença e a determinação da área abaixo da curva de progresso da doença (AACPD). Esta foi calculada pelo somatório das áreas trapezoidais, sendo mensurada de forma adimensional (CAMPBELL \& MADDEN, 1990):

$$
A A C P D=\sum_{i=1}^{n}\left[\left(\frac{y_{i+1}+y_{i}}{2}\right) *\left(t_{i+1}-t_{i}\right)\right]
$$

em que,

$n$ - número de observações;

$y_{i}$ - severidade da doença na "i"-ésima observação; e $t_{i}$ - tempo da "i"-ésima observação.

Avaliou-se também, por ocasião da colheita, a severidade da antracnose nas vagens. A avaliação foi realizada visualmente, empregando-se uma escala de severidade de nove graus, proposta por VAN-SCHOONHOVEN \& PASTOR-CORRALES (1987). Nesta escala, 1 representa ausência de sintomas visíveis; 3 , presença de poucas e pequenas lesões; 5 , presença de várias lesões, geralmente pequenas (menos de $2 \mathrm{~mm}$ de diâmetro); 7, lesões abundantes, de tamanho mediano (mais de $2 \mathrm{~mm}$ de diâmetro); 9 , necrose severa.

A colheita foi realizada entre 90 e 95 DAE. Foram avaliados o número de plantas por metro, o número de vagens por planta, o número de grãos por vagem, a massa de 100 grãos e a produtividade. Para a estimativa dessas duas últimas variáveis, o teor de água dos grãos foi corrigido para 12\% (b.u.).

A parcela foi constituída de quatro fileiras de $5 \mathrm{~m}$ de comprimento. A área útil correspondeu às duas fileiras centrais, sem $0,5 \mathrm{~m}$ de cada extremidade, perfazendo $4 \mathrm{~m}^{2}$. Os dados obtidos foram submetidos à análise de variância, e as médias foram comparadas utilizando-se o teste de Tukey, a 5\% de probabilidade.

Para complementar as avaliações em campo, visando à compreensão dos resultados, foi realizada, em laboratório, a análise do espectro de gotas produzidas pelas três pontas, utilizando-se um pulverizador costal de pressão constante $\left(\mathrm{CO}_{2}\right)$, nas mesmas condições de pressão e velocidade 
empregadas no campo. Para isso, fez-se uso de um analisador de gotas em tempo real (Spraytec, Malvern Instruments), que se baseia na técnica da difração de raio laser. Determinou-se o diâmetro da mediana volumétrica (DMV) e a porcentagem de volume composto por gotas com diâmetro inferior a $100 \mu \mathrm{m}$, de acordo com a metodologia apresentada pela ASAE (2000). Também foi avaliada, em laboratório, a densidade de gotas depositadas em alvo artificial. Essa análise foi realizada a partir da contagem manual das impressões das gotas (gotas $\mathrm{cm}^{-2}$ ) em etiquetas de papel hidrossensível, dispostas ao longo da faixa de aplicação. As pontas foram posicionadas a $50 \mathrm{~cm}$ do alvo.

\section{RESULTADOS E DISCUSSÃO}

A temperatura, a umidade relativa do ar e a velocidade do vento foram favoráveis, durante as aplicações do fungicida: temperatura inferior a $28^{\circ} \mathrm{C}$, umidade relativa superior a $60 \%$ e velocidade do vento

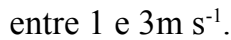

A antracnose (Colletotrichum lindemuthianum (Sacc. \& Magn.) Scrib.) e a manchaangular (Phaeoisariopsis griseola (Sacc.) Ferraris) foram as doenças que atacaram o feijoeiro com maior intensidade. Também houve ocorrência de ferrugem (Uromyces appendiculatus (Pers.) Unger). As três doenças apresentaram os primeiros sintomas na fase inicial do ciclo da cultura (cerca de 20 DAE). Na testemunha, a área foliar afetada pela antracnose variou de $0,7 \%$, aos 30 DAE, a 10,8\%, aos 73 DAE. No caso da mancha-angular, a área variou de $0,2 \%$, aos $30 \mathrm{DAE}$, a $10,3 \%$, aos 73 DAE; e no caso da ferrugem, de $0,8 \%$, aos 30 DAE, a 1,6\%, aos 58 DAE. Aos 73 DAE, a área foliar afetada com ferrugem caiu para $0,9 \%$.

As doenças, nas parcelas tratadas, não apresentaram avanço acentuado ao longo do ciclo, contrastando com o que ocorreu na testemunha (Figura 1). Isso mostra a eficácia do fungicida no controle das doenças, principalmente no da antracnose e da mancha-angular. De maneira geral, as aplicações de fungicida com as três pontas de pulverização não apresentaram grande diferenciação entre si, como pode ser visto nas curvas de progresso das doenças. $\mathrm{O}$ clorotalonil tem sido usado com êxito no controle de doenças do feijoeiro em condições de campo (VIEIRA et al., 1998). O produto apresenta características físicoquímicas, como baixa volatilidade e baixa solubilidade, que auxiliam seu poder fungitóxico.

Não houve diferença de severidade pelo uso das pontas no controle das doenças (Tabela 1). As aplicações do fungicida com as três pontas foram (a)

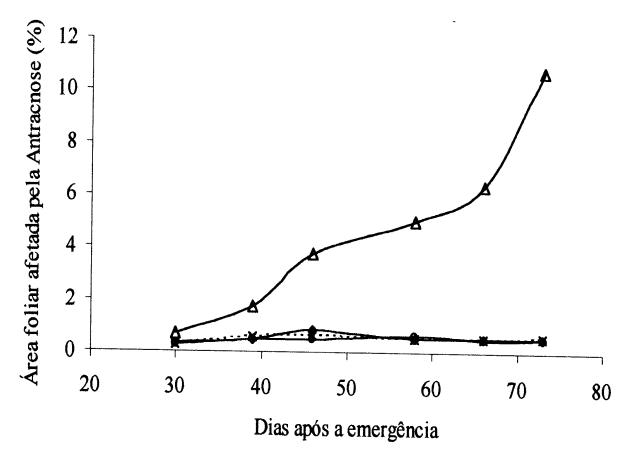

$\begin{array}{ll}\rightarrow \text { Jato Plano Padrão } & \cdots \times \cdots \text { Jato Plano Antideriva } \\ \rightarrow \text { Jato Cônico Vazio } & \rightarrow \text { Testemunha }\end{array}$

(b)

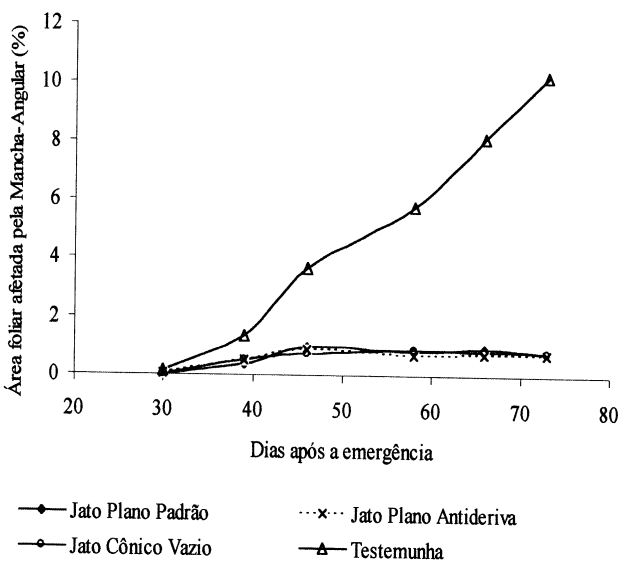

(c)

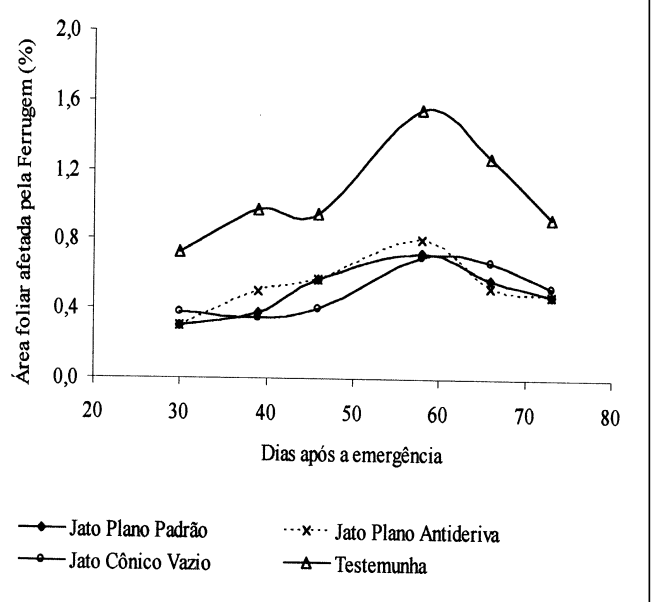

Figura 1 - Efeitos das pontas de pulverização de jato plano padrão, de jato plano antideriva e de jato cônico vazio, utilizadas na aplicação do clorotalonil no feijoeiro, nas curvas de progresso da antracnose (a), da mancha-angular (b) e da ferrugem (c).

Ciência Rural, v.35, n.5, set-out, 2005. 
Tabela 1 - Efeitos das pontas de pulverização de jato plano padrão, de jato plano antideriva e de jato cônico vazio, utilizadas na aplicação do clorotalonil no feijoeiro, na severidade de antracnose nas vagens e na área abaixo da curva de progresso da antracnose, da mancha-angular e da ferrugem, entre 30 e 73 DAE

\begin{tabular}{|c|c|c|c|c|}
\hline \multirow{2}{*}{ Ponta } & \multirow{2}{*}{ Severidade nas Vagens ${ }^{*}$} & \multicolumn{3}{|c|}{ AACPD } \\
\hline & & Antracnose & Mancha-angular & Ferrugem \\
\hline Jato plano padrão & $1,00 b^{* *}$ & $20,01 \mathrm{~b}$ & $31,16 \mathrm{~b}$ & $23,74 \mathrm{~b}$ \\
\hline Jato cônico vazio & $1,25 \mathrm{~b}$ & $16,83 \mathrm{~b}$ & $30,38 \mathrm{~b}$ & $23,18 \mathrm{~b}$ \\
\hline Jato plano antideriva & $1,25 \mathrm{~b}$ & $18,72 \mathrm{~b}$ & $28,80 \mathrm{~b}$ & $23,96 \mathrm{~b}$ \\
\hline Testemunha & $3,75 \mathrm{a}$ & 145,69 a & $216,68 \mathrm{a}$ & $50,18 \mathrm{a}$ \\
\hline
\end{tabular}

* Severidade de antracnose nas vagens, escala de 1 a 9, em que: 1 = ausência de sintomas e $9=$ necrose severa.

** Médias seguidas da mesma letra, nas colunas, não diferem significativamente entre si, a 5\% de probabilidade, pelo teste de Tukey.

superiores à testemunha e iguais entre si no controle da antracnose, da mancha-angular e da ferrugem. A severidade de antracnose nas vagens e a AACPD, para as três doenças, foram maiores nas parcelas que não receberam fungicida.

Em experimentos realizados no Paraná, visando ao controle da mancha-angular e da antracnose, SILVA (1999) também não constatou diferença entre as pontas de jato cônico vazio e de jato plano padrão na eficácia de fungicidas aplicados com diferentes volumes de pulverização. GARCIA et al. (2000), estudando o controle de doenças do feijoeiro com fungicida sistêmico, também não constataram diferenças entre as pontas de jato plano e as de jato cônico vazio.

A população final de plantas variou de 231 a 251 mil plantas ha ${ }^{-1}$ (Tabela 2), situando-se dentro da população de plantas recomendada para a cultura do feijão (VIEIRA, 1978). O número de vagens por planta variou de 4,4 a 6,2; o número de sementes por vagem, de 3,6 a 4,4; a massa de 100 sementes, de 21,3 a $23,1 \mathrm{~g}$ e a produtividade, de 808 a $1.515 \mathrm{~kg} \mathrm{ha}^{-1}$. A produtividade nas parcelas tratadas com fungicida foi, em média, $76 \%$ superior à da testemunha. Os componentes de produção afetados pela aplicação de fungicida foram o número de sementes por vagem e a massa de 100 sementes.
Como ocorreu na avaliação da severidade de doenças, também não houve diferença entre pontas quanto à produtividade da cultura. Tradicionalmente, os agricultores têm utilizado pontas de jato cônico, com volumes de pulverização superiores a 200 $\mathrm{L} \mathrm{ha}^{-1}$, para a aplicação de fungicida. Entretanto, em face dos resultados obtidos, deve-se considerar também a possibilidade de uso de pontas de jato plano, principalmente em condições climáticas adversas, em que o seu emprego pode propiciar redução de deriva.

A ponta de jato cônico vazio produziu gotas de tamanho bastante reduzido (Tabela 3), o que mostra que ela tem alto potencial de deriva. No entanto, a ponta de jato plano antideriva apresentou baixa percentagem do volume pulverizado composto por gotas com diâmetro inferior a $100 \mu \mathrm{m}$, podendo propiciar, portanto, aplicações mais seguras ambientalmente, principalmente em condições climáticas adversas.

A densidade de gotas proporcionada pela ponta de jato plano padrão, de jato plano antideriva e de jato cônico vazio foi de 114, 62 e 232 gotas $\mathrm{cm}^{-2}$, respectivamente. Esses valores encontram-se acima da densidade mínima recomendada para o controle de doenças utilizando fungicidas de contato. Isso pode explicar o controle das doenças obtido nas aplicações do clorotalonil, em campo, utilizando as três pontas. Vários autores citam o intervalo de 50 a 70 gotas $\mathrm{cm}^{-2}$ como a

Tabela 2 - Efeitos das pontas de pulverização de jato plano padrão, de jato plano antideriva e de jato cônico vazio, utilizadas na aplicação do clorotalonil, nos componentes da produção do feijoeiro

\begin{tabular}{|c|c|c|c|c|c|}
\hline Ponta & Plantas ha ${ }^{-1}$ & Vagens planta $^{-1}$ & Sementes vagem $^{-1}$ & Massa de 100 sementes (g) & Produtividade $\left(\mathrm{kg} \mathrm{ha}^{-1}\right)$ \\
\hline Jato plano padrão & 231.250 & 5,9 & $4,2 a^{*}$ & $22,8 \mathrm{a}$ & $1.308 \mathrm{a}$ \\
\hline Jato cônico vazio & 256.875 & 5,6 & $4,2 \mathrm{a}$ & $21,9 a b$ & $1.350 \mathrm{a}$ \\
\hline Jato plano antideriva & 245.000 & 5,9 & $4,4 \mathrm{a}$ & $23,1 \mathrm{a}$ & $1.439 \mathrm{a}$ \\
\hline Testemunha & 240.000 & 4,4 & $3,6 \mathrm{~b}$ & $21,3 \mathrm{~b}$ & $808 \mathrm{~b}$ \\
\hline
\end{tabular}

* Médias seguidas da mesma letra, nas colunas, não diferem significativamente entre si, a 5\% de probabilidade, pelo teste de Tukey. A ausência de letras indica que não houve significância no teste F. 
Tabela 3 - Diâmetro da mediana volumétrica (DMV), percentagem do volume pulverizado composto por gotas com diâmetro inferior a $100 \mu \mathrm{m}$ e densidade de gotas determinados em laboratório, afetados por pontas de pulverização de jato plano padrão, de jato plano antideriva e de jato cônico vazio

\begin{tabular}{lcccc}
\hline Ponta & Pressão $(\mathrm{kPa})$ & $\mathrm{DMV}(\mu \mathrm{m})$ & Volume de gotas menores que $100 \mu \mathrm{m}(\%)$ & ${\text { Densidade de gotas }\left(\text { gotas cm }^{-2}\right) *}^{*}$ \\
\hline Jato plano padrão & 200 & 164 & 15,71 & 114 \\
Jato cônico vazio & 400 & 90 & 54,93 & 232 \\
Jato plano antideriva & 200 & 322 & 6,90 & 62 \\
\hline
\end{tabular}

* Volume de pulverização: $125 \mathrm{~L} \mathrm{ha}^{-1}$

faixa mínima de cobertura do alvo para obter bom controle de doenças com fungicidas de contato (BARTHELEMY et al., 1990; MÁRQUEZ, 1997 e AZEVEDO, 2001).

\section{CONCLUSÕES}

Não houve influência do tipo de ponta de pulverização (jato plano padrão, jato plano antideriva e jato cônico vazio) utilizada na aplicação do fungicida clorotalonil no controle da antracnose, da manchaangular e da ferrugem do feijoeiro. O fungicida propiciou controle das doenças, com reflexo na produtividade, que foi, em média, $76 \%$ superior à obtida na testemunha.

\section{AGRADECIMENTOS}

Ao Conselho Nacional de Desenvolvimento Científico e Tecnológico (CNPq), pela bolsa de doutorado concedida ao primeiro autor.

\section{REFERÊNCIAS}

ASAE - American Society of Agricultural Engineering. Spray nozzle classification by droplet spectra. St. Joseph: ASAE, 2000. p.389-391. (ASAE Standard S572 AUG99).

AZEVEDO, L.A.S. Proteção integrada de plantas com fungicidas. São Paulo, 2001. 230p.

BARTHELEMY, P. et al. Choisir les outilis de pulverisation. Paris: Institut Technique des Céréales et des Fourrages, 1990. 160p.

BORÉM, A.; CARNEIRO, J.E.S. A cultura. In: VIEIRA, C. et al. (eds). Feijão: aspectos gerais e cultura no Estado de Minas. Viçosa, MG : UFV, 1998. p.13-17.

CAMPBELL, C.L.; MADDEN, L.V. Introduction to plant disease epidemiology. New York : John Wiley \& Sons, 1990. 532p.

CHRISTOFOLETTI, J.C. Considerações sobre a deriva nas pulverizações agrícolas e seu controle. São Paulo: Teejet, 1999. $15 \mathrm{p}$.

CROSS, J.V. et al. Spray deposits and losses in different sized apple trees from an axial fan orchard sprayer: 2. Effects of spray quality. Crop Protection, London, v.20, p.333-343, 2001.
DUDIENAS, C. et al. Efeito de fungicidas na produção, sanidade e qualidade fisiológica de sementes de feijão. Fitopatologia Brasileira, Brasília, v.15, n.1, p.20-24, 1990.

GARCIA, L.C. et al. Avaliação da qualidade da aplicação de um fungicida em função do tipo de ponta de pulverização e do estádio de desenvolvimento da cultura do feijão. In: SIMPÓSIO INTERNACIONAL DE TECNOLOGIA DE APLICAÇÃO DE AGROTÓXICOS, 2., 2000, Jundiaí. Anais... Jundiaí: IAC, 2000. Capturado em 6 out. 2002. Online. Disponível na Internet: http://www.iac.br/ cma/Sintag.

GODOY, C.V. et al. Diagrammatic scales for bean diseases: development and validation. Zeitschrift fur Planzenkrankheiten und Pflanzenschutz, Sonderheft, v.104, n.4, p.336-345, 1997.

JOHNSON, M.P.; SWETNAM, L.D. Sprayer nozzles: selection and calibration. Lexington: University of Kentucky, 1996. 6p. Capturado em 6 ago. 2002. Online. Disponível na Internet: http://www.uky.edu/Agriculture/Pat/pat3.pdf.

MÁRQUEZ, L. Tecnología para la aplicación de defensivos agrícolas. In: CONGRESSO BRASILEIRO DE ENGENHARIA AGRÍCOLA, 26., 1997, Campina Grande. Anais... Campina Grande: UFPB, 1997. CD-Rom.

MURPHY S.D. et al. The effect of boom section and nozzle configuration on the risk of spray drift. J Agric Engng Res, London, v.75, p.127-137, 2000.

SDTF - Spray Drift Task Force. A summary of ground application studies. Missouri: SDTF, 1997. 6p.

SILVA, O.C. Tecnologia de aplicação de fungicidas. In: CANTERI, M.G. et al. (eds). Principais doenças fúngicas do feijoeiro. Ponta Grossa: UEPG, 1999. p.127-137.

VAN-SCHOONHOVEN, A.; PASTOR-CORRALES, M.A. Sistema estándar para la evaluación de germoplasma de frijol. Cali: CIAT, 1987. 56p.

VIEIRA, C. A cultura do feijão. Viçosa: UFV, 1978. 146p.

VIEIRA, R.F. et al. Avaliação da eficiência de fungicidas e do inseticida Cartap no controle de doenças da parte aérea do feijoeiro (Phaseolus vulgaris) no inverno primavera. Summa Phytopathologica, Jaguariúna, v.24, n.1, p.17-22, 1998.

WALKLATE, P.J. A simulation study of pesticide drift from an air-assisted orchard sprayer. J Agric Engng Res, London, v.51, p.275-284, 1992.

WOMAC, A.R. et al. Comprehensive evaluation of droplet spectra from drift reduction nozzles. St. Joseph: ASAE, 1997. 47p. (ASAE Paper n.97-1069). 